

\section{ÍNDICE}

\section{ÁMBITOS PERSONALES PERSONAL ÁMBITOS}

Crisis de Venezuela: Análisis y perspectivas según los titulares de la prensa argentina, española y china

Venezuela's crisis: Analysis and perspectives in the headlines of Argentine, Spain and China press

Hui Feng Liu

Tratamiento informativo de la violencia de género: asesinatos de mujeres. Análisis de la agencia EFE

Informative treatment of gender violence: murders of women. Analysis of the press agency EFE Rosa Rodríguez Cárcela, Agustín López Vivas

MONOGRAFICOS MONOGRAPHS

Presentación Monográfico. El universo transmedia de los medios de comunicación universitarios: acción dentro y fuera del aula en la sociedad postdigital

Antonia Isabel Nogales-Bocio, Ángels Álvarez villa

El papel transformador de la radio universitaria en materias teóricas ajenas a la comunicación

The transformative role of college radio in theoretical subjects outside communication

Miguel Ángel Díaz Monsalvo

La radiodifusión universitaria: acción discursiva radiofónica para la divulgación de la ciencia University Radio Broadcasting: Radiophonic Discursive Action for the Science Popularization Jorge Sadi Durón, Joel Zapata Salazar

El uso corporativo de Instagram en las universidades privadas españolas. Estudio comparativo de treinta y cinco universidades

The corporate use of Instagram in spanish private universities. Comparative analysis of thirty-five private universities 
La radio universitaria como herramienta de inclusión social: OndaCampus en contextos como la cárcel y barrios desfavorecidos

The university radio as a tool for social inclusion: OndaCampus in contexts like the prison and disadvantaged neighborhoods

Leonor Real Adame, Daniel Martín-Pena, Macarena Parejo Cuéllar

Hacer radio universitaria en la era de YouTube: uso de la plataforma de vídeos a demanda en el contexto mexicano

Make college radio in the age YouTube: use of video on demand platform in the Mexican context Marina Vázquez Guerrero

\section{ARTÍCULOS ARTICLES}

O impresso e o digital nos modelos de negócios de jornais locais: uma análise do Sermos Galiza

The press and digital in business models from local media: Analysis of newspaper Sermos Galiza

Giovanni Ramos

Publicidad y cáncer en la prensa escrita (1903-1912)

Advertising and cancer in the written press (1903-1912)

Laura Almudéver-Campo, Ramón Camaño-Puig

Game rules vs. fandom. How Nintendo's Animal Crossing fan-made content negotiates the videogame meanings

Las reglas del juego vs. el fandom. Cómo el contenido hecho por fans de Nintendo Animal Crossing negocia los significados del videojuego

Jose A. Moreno

La comedia de situación y su análisis textual: evolución de los elementos constructivos del formato

The sitcom and its textual analysis: evolution of the constructive elements of the format

Darío Martín Sánchez

Análisis del discurso emocional de Donald Trump en la campaña electoral de $\mathbf{2 0 1 6}$ Analysis of Donald Trump's emotional speech on the 2016 election campaign 
Innovar, comunicar y transformar (en) la Universidad

Innovate, communicate and transform (at) the University

María Sofía Bernat

288-292

Transparencia en los medios: Un requisito imprescindible para medir la rentabilidad social en radio y televisión

Transparency in the media: An essential requirement to measuresocial profitability in radio and television

Amanda Salazar

Los estudios feministas en comunicación: representación de las mujeres en la revolución tecnológica

Feminist studies in communication: representation of women in the technological revolution 


\title{
O impresso e o digital nos modelos de negócios de jornais locais: uma análise do Sermos Galiza
}

\author{
The press and digital in business models from local media: \\ Analysis of newspaper Sermos Galiza
}

\author{
Giovanni Ramos, Universidade da Beira Interior, \\ Convento de Sto. António, 6201-001. Covilha. Portugal \\ gio@gioramos.net | Orcid: https:/orcid.org/0000-0001-5696-2987
}

DOI: http://dx.doi.org/10.12795/Ambitos.2020.i47.09

\begin{abstract}
Resumo
Compreender qual o papel do jornalismo impresso nos meios de comunicação de proximidade nos dias atuais é o principal objetivo desta comunicação. Diante de problemática da diminuição do interesse do público pelos media em papel e da dificuldade dos jornais, sobretudo do jornalismo local ou de proximidade de transformarem suas plataformas digitais em modelos de negócio sustentáveis financeiramente, busca-se estudar um caso de jornal local impresso/digital que esteja em crescimento econômico para conhecer suas rotinas, práticas e qual é a função do impresso e a função do digital na arrecadação de recursos. O estudo de caso escolhido foi o Sermos Galiza de Santiago de Compostela, Galícia, Espanha. Um nativo impresso/digital com planos de tornar-se diário impresso. A metodologia utilizada nesta pesquisa incluiu uma observação participante da redação do jornal, uma entrevista com diretores da empresa além da bibliografia sobre jornalismo de proximidade, jornalismo digital e modelos de negócios no jornalismo. A observação foi feita inicialmente e o relatório da observação serviu para a construção das
\end{abstract}


perguntas do questionário utilizado na entrevista. Buscou-se, além das fontes de receita, como era a rotina para a produção de notícias para cada plataforma, se os jornalistas eram os mesmos, qual era a prioridade e qual a importância da versão digital para as receitas da empresa, já que o conteúdo disponibilizado é completamente gratuito. Com as informações obtidas na observação e na entrevista aliada as teorias estudadas na revisão bibilográfica, o resultado do estudo apontou que o jornal estudado distingue completamente impresso e digital em seu conteúdo e possui as receitas focadas nas assinaturas da versão impressa, com o conteúdo digital focado em hard-news gratuito, convidando o leitor e conhecer e assinar o impresso, onde recebe grandes reportagens e entrevistas, um conteúdo premium não disponibilizado entre as notícias do website.

\begin{abstract}
Understanding the role of press journalism in today's media is the main purpose of this paper. Faced with problems of diminishing public interest in press media and the difficulty of newspapers, especially local journalism or proximity to transform their digital platforms into financially sustainable business models, we seek to study a local press / digital newspaper case that is in economic growth to know its routines, practices and what the function of the print and the function of the digital in the collection of resources. The case study chosen was the Sermos Galiza of Santiago de Compostela, Galicia, Spain. A press/ digital native with expected to become a daily press. The methodology used in this research included a participant observation of the newspaper's writing, an interview with directors of the company, and a bibliography on proximity journalism, digital journalism and business models in journalism. The observation was made initially and the observation report served to construct the questions of the questionnaire used in the interview. In addition to media sources of the newspaper, as was the routine for the production of news for each platform, if the journalists were the same, what was the priority and how important was the digital version for the revenue from the company, since the content provided is completely free. With the information obtained in the observation and in the allied interview with the theories studied in the bibilographic review, the results of the study indicated that the journal studied completely distinguishes press and digital content and has the revenues focused on the subscrptions of the press version, with digital content focused in free hard-news, inviting the reader and knowing and signing the form, where it receives great reports and interviews, premium content not available between the news of the website.
\end{abstract}

Palabras clave: Jornalismo de proximidade, jornalismo local, modelos de negócios, jornalismo digital, Sermos Galiza

Keywords: Proximity media, local media, business models, digital journalism, Sermos Galiza 


\section{INTRODUÇÃO}

O jornalismo impresso perde força no mundo desde a década de 90 , quando a internet começou a ser comercializada em residências. Entre os anos de 1990 e 2014, 25\% dos jornais impressos dos Estados Unidos deixaram de circular (Stephens, 2014). Em Portugal, a tiragem de exemplares dos principais jornais generalistas continua em queda. De 2015 para 2016 , a redução foi de $5,38 \%$ no número total de exemplares dos jornais diários. De 2016 para 2017, a queda foi ainda maior: 8,7\% (Durães, 2017). Já o Brasil, oito jornais fecharam as portas entre 2009 e 2016 (Pacete, 2015), com 1,4 mil jornalistas perdendo o emprego somente em 2015 (Borges, 2016).

A crise nos meios impressos abre novas possibilidades no mundo digital. Dados da Associação Portuguesa de Controlo de Tiragens (APCT) mostram que o número de assinaturas digitais dos jornais generalistas de Portugal cresceu $135 \%$ no primeiro semestre de 2014, comparado ao ano anterior (Pereira, 2014). Dados também da APCT mostram que em 2016, o semanário Expresso teve um aumento de 27,82\% no número de assinaturas digitais. São mais de 21 mil assinantes digitais, mais que a soma dos concorrentes no mesmo segmento.

O New York Times conseguiu só nos três primeiros meses do ano, 308 mil novos assinantes nesta modalidade e o digital permitiu a volta dos lucros da empresa, que apresentou resultados líquidos de U\$13 milhões este ano (Nunes, 2017).

O crescimento dos jornais portugueses na internet e o exemplo do New York Times apontam um caminho. Porém, as adversidades que o jornalismo encontra nas plataformas digitais é apresentada no Digital News Report 2017 Espanha , produzido por pesquisadores do Center for Internet Studies and Digital Life da Faculdade de Comunicação da Universidade de Navarra a partir de um estudo feito pela Universidade de Oxford em 2016. O estudo apontou que entre os espanhóis que consumem informações pela internet, $50 \%$ evitam ler notícias por diversas razões, 53\% não paga para se informar (em meio nenhum), 9\% pagou por algum tipo conteúdo digital em 2016 e 57\% acha muito improvável que vá pagar alguma informação digital em 2017.

A dificuldade das empresas de comunicação para se sustentarem financeiramente no meio digital é ainda maior no chamado jornalismo local. Para Hindman (2015), o problema maior do local é que a internet possui sua base financeira a partir de largas escalas, algo distante destes jornais que, somadas as audiências dos locais em todo o mundo, correspondem a apenas $1 \%$ do tráfego mundial e uma média de cinco minutos por mês dos usuários de internet. 
Bastos (2006), entende que o ciberjornalismo em Portugal ainda não possui resultados animadores, sobretudo no interior, devido a um conservadorismo tanto das empresas quanto dos jornalistas, além da falta de um modelo de negócio sustentável e de baixos investimentos, tanto em equipe, quanto nos sites dos jornais.

Outro problema encontrado na imprensa local portuguesa é no aproveitamento das ferramentas e possibilidades existentes no ciberjornalismo. Segundo Jerónimo (2015), diversos estudos feitos na área apontam que os jornais locais portugueses produzem poucos conteúdos exclusivos para a web, com pouca multimedialidade e hipertextualidade, além de uma baixa interatividade com o seu público. Jerónimo destaca ainda que a prioridade dos meios de comunicação locais de Portugal pelo formato impresso é normal visto que a internet não faz parte da vida dos habitantes de todos os municípios.

Para fazer o estudo de caso, definiu-se como critérios os seguintes: a) ser um jornal que possua edição impressa, mas que tenha forte presença no meio digital; b) ser uma empresa não ligada a um conglomerado de comunicação, que sobreviva com recursos próprios e que tenha uma redação profissional, formada por jornalistas.

A região escolhida para este projeto foi a Comunidade Autônoma da Galícia na Espanha que possui imprensa digital regional desde 1995 (García e Negreira-Rey, 2016). O veículo escolhido foi o Sermos Galiza de Santiago de Compostela, fundado em 2012 como um semanário e portal de notícias, isto é, um nativo digital mesmo possuindo uma versão impressa.

\section{REVISÃO TEÓRICA}

O jornalismo impresso acompanhou a internet desde antes de ela ser popularizada através do protocolo HTML na década de 90. Segundo Pinheiro (2009), o primeiro jornal a fazer uma experiência pela rede foi o americano The San Francisco Examiner em 1981.

Em 1985 na Inglaterra, o The Guardian desenvolveu o World Reporter, com o objetivo de publicar na rede materiais completos não apenas do seu diário, mas de outros tabloides do país (Junior, 2007). O pioneirismo do jornalismo digital no Brasil foi da Agência Estado, de propriedade do Jornal Estado de São Paulo, com o projeto Notícias do Futuro desenvolvido na década de 80 (Pereira, 2002).

O primeiro jornal a ter uma versão digital na internet usando o protocolo HTML foi o americano The San Jose Mercury News em 1993. Na Espanha, o primeiro jornal a ter a sua versão digital na internet foi o semanário El Temps, da Comunidade Valenciana, em novembro de 1994. O primeiro diário a migrar para a internet foi o El Comercio da cidade 
de Gijón, Comunidade Autónoma das Astúrias, em janeiro de 1995, seguido do Avui, da cidade de Barcelona, Comunidade Autónoma da Catalunha, em abril de 1995 (Salaverría, 2016).

A queda na audiência dos jornais impressos começou na segunda metade do século XX, com a popularização do rádio e a televisão. Mendes (2012) afirma que a queda entre as décadas de 50 e 90 nos Estados Unidos foi de 34\%. Apesar disso, a receita dos jornais se manteve e até subiu devido ao crescimento do mercado publicitário.

A entrada dos jornais na internet, sobretudo a partir da segunda metade da década de 90, fez com que se apostasse no crescimento do jornalismo digital como um negócio lucrativo. Em 2006, o anuário Annual Report of the American Journalism do Pew Research Center apontava que em 2004 os negócios do jornalismo impresso valiam 36 vezes mais do que o jornalismo online. Porém, a projeção para 2018 era que a internet ultrapassasse e recebesse um investimento maior que os jornais impressos (Canavilhas, 2007).

A queda nas receitas dos jornais começou a ganhar força após a crise econômica de 2008. Segundo Mendes (2012), dois setores da economia que estavam entre os que mais investiam no mercado publicitário, a indústria do automóvel e o imobiliário, entraram em colapso. A crise na publicidade afetou a receita dos meios de comunicação impressos, que tinham na venda de anúncios a sua principal fonte de receita.

Mendes (2012) explica que as receitas dos jornais impressos sempre seguiram uma lógica chamada de $80 / 20$ : $80 \%$ dos recursos oriundos da publicidade e $20 \%$ da circulação, isto é, assinaturas e venda avulsa dos exemplares. Este formato permitiu que o preço do jornal tornasse mais popular, em alguns casos, pudesse ser distribuído gratuitamente.

Se a mídia impressa tornou-se menos atrativa para o mercado publicitário, a mídia digital também não foi o alvo principal dos anunciantes. O relatório do Pew Research Center dos Estados Unidos de 2016 apontou o crescimento do investimento publicitário em mídia digital, com U\$ 59,6 bilhões. Outro relatório, publicado pela Associação Mundial de Jornais e Publishers de Jornais (WAN-IFRA) em 2015 a partir de um estudo em 70 países apontou que a publicidade na internet dos jornais cresceu $8 \%$ entre 2010 e 2014. Da publicidade, a maior parte da receita foi para as plataformas Google (38\%) e Facebook (10\%).

O baixo investimento da publicidade em meio digital tem causa no formato de distribuição. Hindman (2015) associa a lucratividade na web com a distribuição em larga escala do seu produto, algo que a Google e as redes sociais como o Facebook possuem, mas os jornais não. 
Costa (2014) lembra que, no mercado digital, os jornais possuem outros concorrentes, que ficam com a maior parte dos recursos. Ele cita um levantamento do Boston Consulting Group em que a indústria de produção de conteúdo fica com apenas $7 \%$ das receitas nos negócios digitais em todo o mundo, enquanto $60 \%$ vai para as empresas de telecomunicações e $14 \%$ para a indústria de aparelhos digitais.

Das empresas de telecomunicações, Costa (2014) destaca os agregadores de conteúdos. Redes sociais como o Facebook, buscadores como o Google, lojas de comércio eletrônico como a Amazon e portais integradores de conteúdos como o brasileiro UOL, o americano AOL e o espanhol Terra ficam hoje com $22 \%$ do faturamento digital, à frente dos jornais e produtores de informação.

\subsection{Financiamento da imprensa}

A popularização da internet comercial a partir dos anos 90 alterou os padrões de escala, produção, distribuição e valor dos produtos comercializados. Na rede, o público consumidor possui acesso mais rápido aos produtos, muitas vezes não quer pagar por eles e o comércio tornou-se global. Os fatos obrigaram as empresas a reverem suas estratégias tanto no planejamento da venda, quanto na criação de valor dos seus produtos (Silva, 2015).

Por outro lado, o crescimento das empresas de Tecnologia da Informação e Comunicação (TIC) permitiram que os meios de comunicação tivessem novos canais tanto com o público consumidor, quanto com outros parceiros, o que possibilitou a criação de novos produtos e novas possibilidades de se obter renda e lucros (Orofino, 2011).

No caso do jornalismo, os jornais impressos que migraram para a internet ficaram diante de um dilema: trabalhar com duas plataformas diferentes e buscar a rentabilidade em ambos, sendo que uma é cada vez menos atrativss aos leitores e a segunda possui concorrências com outras estruturas.

Um dos caminhos apontados para esses jornais é apresentado por Osterwalder e Pigneur (2011), que intitulam de plataformas multilaterais, quando uma empresa possui dois produtos distintos, mas que precisam de uma estratégia conjunta para funcionarem.

Os autores citam o jornal sueco Metro, que era distribuído gratuitamente em estações de trem e ônibus. Houve um subsídio da empresa para o público leitor, retirando a cobrança do produto, o que tornou-se popular e atraiu outro segmento da empresa: os anunciantes.

Além da plataforma multilateral, o caso do jornal Metro se enquadra também em outro padrão de Osterwalder e Pigneur (2011), chamado de "grátis como modelo de negócios", 
cuja característica principal é o subsídio completo de um segmento como estratégia de vendas.

Os autores afirman que o padrão grátis foi utilizado pelos jornais nos anos 90 , mas perdeu força com a internet, que afetou o valor do produto notícia: um jornal grátis perdia o seu diferencial com a quantidade de conteúdos gratuitos digitais.

Diante deste cenário, o grátis passou a ser utilizado dentro dos modelos de negócios como uma estratégia inicial para atrair o cliente, mas com outras alternativas para obter recursos. Entre as propostas, estão ações utilizadas tanto no mercado de comunicação quanto de tecnologia da informação.

Se por um lado o jornal grátis não possui mais a atração de antes, no digital, o público resiste por cobranças por conteúdo, como assinaturas digitais, financiamentos coletivos e micropagamentos (Mendes, 2012). Para o jornalista Ricardo Simões Ferreira, diretor digital do Diário de Notícias, a população em geral tem a ideia do conteúdo como um direito adquirido e por isso mantém uma resistência para pagar por um produto que não seja físico.

A internet é entendida, quase universalmente, como uma plataforma gratuita. Os utilizadores aceitam pagar para ter acesso a ela, mas levam a mal quando lhes tentam cobrar o que fazem - ou veem, ou ouvem, ou escrevem - dentro dela. A net é cada vez mais um "serviço básico": assumimos que existe, reclamamos se tem um problema, não sabemos viver sem ela e não queremos pagá-la (Ferreira, 2017).

Entre as formas de cobranças pelo conteúdo, o paywall o modelo mais frequente. A tradução literal para o termo inglês é muro de pagamento. O modelo consiste em restringir o conteúdo para os assinantes. O usuário acessa a página inicial ou outra página de manchetes do jornal na internet, mas precisa de um cadastro, no caso a assinatura, para ler o conteúdo (Mendes, 2012).

Porém, para enfrentar a resistência do público com pagamentos, muitos jornais optam pelo freemium, uma junção das palavras free e premium. Comum no setor de tecnologia na venda de softwares, o freemium se caracteriza no jornalismo por permitir parte do conteúdo de forma gratuita, com apenas alguns setores da página reservado a assinantes. Gascón (2010) explica que os editores são quem fazem a seleção do que será gratuito e do que será pago e normalmente os conteúdos premium "são exclusivos, úteis e feitos por autores selecionados, com um valor progressivo da notícia" (Gascón, 2010:123). 
O financiamento coletivo ou crowdfunding é outro método utilizado por profissionais de comunicação para obter receita junto ao público, neste caso sem a necessidade de restrição de conteúdo. Utilizado não apenas no jornalismo, mas para outros projetos, o crowdfunding consiste em abrir campanhas onde o público financia projetos com pequenas quantidades em troca, muitas vezes, de pequenas recompensas (Mendes, 2012).

\subsection{Jornalismo de proximidade}

Uma sociedade cada vez mais globalizada, com as informações sendo transmitidas em alta velocidade, o papel do jornalismo em âmbito regional torna-se cada vez mais necessário como uma forma de preservação das identidades culturais (Bahia, 2009). Couto (2010) cita o termo glocalização do sociólogo inglês Roland Robertson (1995), uma convergência da globalização com a regionalidade. Quanto maior a globalização, mais valorizado fica o regionalismo e os veículos de comunicação locais desempenham um papel estratégico na valorização das informações e culturas regionais.

Além do jornalismo local, há outro conceito próximo utilizado para definir o gênero: jornalismo de proximidade. Jerónimo (2015) explica que há autores que colocam os termos como sinônimos e outros fazem a distinção dos conceitos, diferenciando principalmente local e proximidade.

O jornalismo de proximidade mantém as características do jornalismo local, porém, em um conceito mais amplo. Camponez (2002) aponta o jornalismo de proximidade com um elo de ligação de pessoas que habitam uma comunidade ou que já habitaram, neste caso, abrangendo também emigrantes desta comunidade para outras regiões. Garcia (2012) distingue o jornalismo de proximidade do local pela questão física, isto é, uma comunidade não precisa estar ligada apenas por uma proximidade física, mas também por questões de identidade cultural.

As relações mais próximas entre o jornal e a sua comunidade é a principal característica do jornalismo local. Correia (1998) destaca a presença dos leitores e assinantes na linha editorial do veículo como marca deste jornalismo, mais especificamente do que o autor chama de "elite regional". Correia ainda destaca a importância da venda de assinaturas como componente das receitas do jornal. Esta importância dá-se pelas poucas condições de venda de espaços publicitários, já que o mercado é menor que em um jornal generalista nacional. Esta participação dos leitores no dia-dia do jornal afeta diretamente o conteúdo.

Franklin e Murphy (1991) buscam definir o jornalismo local a partir da conceituação do que é uma notícia local. A história só pode ser considerada local quando ela se aplica a algum 
aspecto da região de abrangência do veículo. Neste caso, uma notícia nacional pode ser inclusa no jornalismo regional quando ela é produzida com um ângulo regional assim como um fato local pode se transformar em notícia nacional ou mesmo internacional pela forma em que for abordada.

O mercado publicitário pequeno com a consequente importância das assinaturas nas receitas do jornal traz uma característica negativa comum no jornalismo local: a proximidade exagerada com o poder político local e uma dependência estatal. Jerónimo (2015) destaca que os jornais locais costumam ser dependentes de agendas institucionais de estruturas públicas, principalmente de câmaras municipais. A dependência dos jornais com publicidades estatais retira a independência editorial gerada pelas assinaturas, sobretudo quando o veículo de comunicação pretende abordar denúncias contra as instituições públicas (Bahia, 2009).

As dificuldades financeiras no jornal local se acentuam quando há concorrência dentro da mesma localidade. A limitação do mercado publicitário faz com que a disputa seja um jogo de soma zero, quando um jornal ganha mais, o outro perde (Franklin, Murphy, 1991).

\section{METODOLOGIA}

Para compreender modelos de negócios para jornais regionais impressos que migraram para a internet ou nasceram híbridos, foi feito um estudo de caso do semanário espanhol Sermos Galiza. O estudo de caso busca conhecer as estratégias para obtenção de receitas financeiras, a relação do meio de comunicação com a comunidade de abrangência e as suas práticas jornalísticas, especialmente na versão digital.

Stake (2016) afirma que um estudo de caso não tem o objetivo de entender outros casos, isto é, não funciona como amostragem, nem representa outras situações. Em um estudo intitulado intrínseco, como o proposto neste artigo, o caso é pré-selecionado para compreender melhor as suas características e não serve para generalização. Por isso, o estudo de um jornal não tem a intenção ser uma base ou exemplo para outros jornais regionais. Ação vista compreender a situação específica do caso escolhido.

O jornal escolhido para o estudo é o Sermos Galiza, com sede em Santiago de Compostela, Comunidade Autónoma da Galícia, Espanha. O medium atua desde 2012 com um semanário impresso e um jornal digital. As razões da escolha se devem a proximidade geográfica, que permitisse que parte dos estudos ocorrem no concelho onde o jornal está sediado, o idioma adotado pelo meio, o galego, mais próximo da língua portuguesa e o material bibliográfico a respeito da imprensa local. 
A investigação qualitativa deste estudo de caso busca a validação das hipóteses através de uma triangulação metodológica (Stake, 2016). Além da revisão bibliográfica, foi utilizado também uma investigação empírica, que teve como instrumentos de coleta uma entrevista com a direção do jornal Sermos Galiza e uma observação participante na redação do jornal para compreender o objeto. Neste caso, compara-se o que o jornal se propõe como empresa (entrevista), o que pratica diariamente na produção dos seus produtos (observação participante) tendo como validação, as teorias a respeito do modelo de negócios e jornalismo regional.

Segundo Braga e Tuzzo (2016), a revisão bibliográfica permite o suporte para que a investigação empírica possa ocorrer, pois trata da estruturação dos conceitos que serão utilizados durante a coleta de dados e análise do material. No caso deste artigo, a revisão bibliográfica será utilizada para enquadrar o jornal dentro dos modelos de negócios e para validar ou não as hipóteses em respeito a impresso e digital, ciberjornalismo e relações com a comunidade.

A primeira coleta de dados empírica consistiu em uma observação da redação do jornal Sermos Galiza. Segundo Bezerra (2010), a observação é um método de investigação etnográfica comum nas Ciências Sociais, mais especificamente na Antropologia. O antropólogo polonês Bronisław Malinowski foi quem deu legitimidade a este método, que consiste na presença do investigador convivendo junto ao grupo de pessoas por um determinado tempo, na busca de dados e informações sobre rotinas e hábitos dos estudados.

Segundo Godoy (1995), a observação pode ser dividida em dois tipos: a não participante, quando o investigador não interage com o objeto a ser estudado em nenhuma hipótese e a participante, quando o investigador, de alguma forma, participa do meio que está observando. Decidiu-se por aplicar uma observação participante neste caso por dois motivos: a necessidade de fazer perguntas para os integrantes da redação durante o processo, perguntas que ajudaram na construção da entrevista com a direção do jornal e um pedido do próprio meio de comunicação, que não se sentiria à vontade com uma observação silenciosa.

Fino (2008) cita Adler e Adler (1987) para explicar os três tipos de observação participante: periférica, ativa e completa. O primeiro confere menor participação ao investigador junto ao público estudado. Há interação, diferente da observação não participante, porém o observador não ocupa o centro das rotinas. 
A observação participante ativa tem a interferência direta do investigador, que assume uma função no processo de rotina dos estudados, porém com distância do centro das decisões. Já na observação participante completa, o investigador é peça-chave no processo das rotinas que irá observar.

No caso do jornal Sermos Galiza, a observação participante escolhida foi a periférica, acompanhando diariamente a rotina de trabalho dos jornalistas, porém sem assumir funções e responsabilidades no processo. A única interação direta ocorrida foi a revisão de textos em língua portuguesa que o jornal publicou.

Após a observação participante foi feita a entrevista com a direção do jornal. Ela ocorreu no dia 24 de julho de 2017 e foi feita com o jornalista responsável pela edição digital, Xosé Mexuto e com o Administrador do jornal, responsável pela parte administrativa e comercial, Roberto Vilameá.

A entrevista como método de investigação permite a exploração de critérios subjetivos, pois o investigador consegue não apenas os dados que procura, mas também interpretações sobre eles. A medida que as respostas as perguntas são apresentadas, é possível refletir sobre os dados analisados, o que possibilita uma análise mais ampla do que é investigado (Temer e Tuzzo, 2017).

\section{RESULTADOS}

\subsection{Jornalismo digital na Galícia}

A primeira experiência de um jornal na internet na Comunidade Autônoma da Galícia, Espanha, foi em 1995 com o El Correo Galego. Em 1996 entrou no ar o primeiro nativo digital, o Vieiros. Entre 1998 e 2000, outros seis jornais impressos da região entram para o digital (Negreira-Rey, 2017).

Para Garcia (2008), apesar de o primeiro jornal galego no digital ter ocorrido no mesmo do resto da Espanha, a imprensa galega demorou para se habituar no mundo digital devido a problemas como a baixa oferta de internet para a população na Galícia durante os primeiros anos. Segundo Negreira-Rey (2017), a crise econômica mundial a partir de 2008 afetou o mercado de jornalismo impresso na Galícia e forçou os meios a apostarem no meio digital. No entanto, a maioria dos veículos faz pouco proveito das potencialidades da internet como a hipertextualidade, interação e produção multimídia.

Negreira-Rey (2017) destaca ainda que o surgimento dos meios Praza Pública, Dioivo e Sermos Galiza a partir de 2012 abriu uma nova perspectiva para a imprensa em galego. Os 
veículos apostaram na aproximação do público e uma rede de colaboradores no modelo de negócio, como forma de driblar a crise financeira.

De acordo com o Mapa dos Medios Galegos produzido pela Universidade de Santiago de Compostela, a Galícia possuía até 31 de março de 2018, 159 veículos de comunicação, 145 com plataforma digital. Quase a metade dos veículos registrados no levantamento atuam somente pela internet e quase um terço é possui suporte impresso e digital, sendo os dois modelos predominantes na imprensa galega.

O Mapa dos Médios Galegos mostra também, o crescimento dos chamados jornais nativos digitais. São 70 jornais que surgiram na internet contra $89 \mathrm{com}$ origem em outras plataformas. O idioma galego é predominante na comunidade: metade dos media (79) informam apenas em galego e outros 46 são ofertados tanto em espanhol quanto o galego. A predominância do galego ocorre sobretudo nos veículos nativos digitais. Dos 79 meios de comunicação que utilizam apenas este idioma, 40 atuam somente na internet.

\subsection{O Sermos Galiza}

A Sermos Galiza S/A é uma empresa jornalística de capital aberto fundada no início de 2012 em Santiago de Compostela, Comunidade Autónoma da Galícia, Espanha, por um grupo de 12 pessoas que tinha como objetivo ter uma publicação impressa no idioma galego. A primeira edição digital foi ao ar em 26 de abril de 2012 e a primeira edição impressa foi publicada no dia 8 de junho de 2012 (Vilameá, entrevista pessoal, julho 24, 2017).

Atualmente, a empresa possui 900 acionistas e um conselho de administração formado por 12 pessoas. O jornal possui 10 funcionários, sendo seis contratados de forma efetiva e quatro de forma autónoma. A edição impressa é semanal e circula às quintas-feiras. Já a edição digital é diária e atualizada em tempo real (Vilameá, entrevista pessoal, julho 24, 2017).

A edição impressa possui uma tiragem média de 2 mil exemplares, sendo 1,2 mil para assinantes. A edição digital possuía em 2017, uma média de 500 mil visualizações de página por mês. O Sermos Galiza anunciou em novembro de 2017, a intenção de transformar a edição impressa em diário a partir de 2019.

Além do capital dos acionistas, a empresa possui como fontes de receitas as assinaturas da edição impressa, a venda de exemplares avulsos da edição impressa, a publicidade nas 
duas versões, a venda de livros editados pelo jornal e uma subvenção do governo da Comunidade Autónoma da Galícia para publicações no idioma galego.

As assinaturas e a publicidade para as versões impressa e digital constituem as maiores fontes de receitas conforme informações de Vilameá (entrevista pessoal, julho 24, 2017).

Tabla 1

Fontes de receita do Sermos Galiza

\begin{tabular}{|l|c|}
\hline \multicolumn{1}{|c|}{ Fonte de receita } & Arrecadação média anual* $^{*}$ \\
\hline Assinaturas & $150.000 €$ \\
\hline Venda avulsa - edição impressa & $* *$ \\
\hline Publicidade (impressa e digital) & $100.000 €$ \\
\hline Livros & $5.000 €$ \\
\hline Subvenção em prol do galego & $32.000 €$ \\
\hline
\end{tabular}

* valores deduzidos de impostos

** o gerente Roberto Vilameá não soube responder os valores.

Principal fonte de receita em 2017, as assinaturas constituem a principal estratégia financeira da empresa. Em julho de 2017, o jornal possuía 1,2 mil assinantes. Cada assinatura custa $155 €$ e o assinante recebe em um ano, 50 edições do semanário mais quatro presentes entre livros e DVDs. Vilameá (entrevista pessoal, julho 24, 2017) entende que o preço da assinatura anual não é barato, mas os leitores entendem o cenário e apoiam o trabalho feito pelo jornal pela sua qualidade e importância.

Destaca-se ainda no jornal Sermos Galiza, há o fato que o meio de comunicação possui 1,2 mil assinantes e 900 acionistas. Vilameá (entrevista pessoal, julho 24, 2017) afirma que há acionistas que não assinam, mas a sua grande maioria sim. O administrador não soube responder exatamente qual o número de acionistas que não assinam o semanário impresso.

A versão digital possui conteúdo aberto e gratuito e não há interesse da empresa, por ora, de restringir o material online para assinantes. Mexuto (entrevista pessoal, julho 24, 2017) 
explica que diferente da edição impressa, que trabalha com material exclusivo, a versão digital possui material mais simples, que não compensaria a cobrança.

A publicidade do jornal possui uma contabilidade integrada para as duas versões, por isso, Vilameá (entrevista pessoal, julho 24, 2017) não soube responder em números qual a porcentagem de arrecadação da versão impressa e da versão digital. O gerente garante, no entanto, que a maior parte dos recursos são dos anúncios publicados no papel, cerca de dois terços, e que o jornal pretende separar a contabilidade para saber exatamente quanto cada formato arrecada.

Vilameá (entrevista pessoal, julho 24, 2017) confirma que a versão impressa é responsável pela entrada de receita na empresa, mas entende que o digital tem sua importância de forma indireta. Para o gerente, os leitores sabem que as assinaturas do papel ajudam a manter a página na internet com conteúdo gratuito.

Mexuto declara ainda, que a versão digital aberta permite as propostas editoriais do Sermos Galiza alcancem um público maior, não apenas residindo na Galícia, mas também de galegos migrantes para outros países. "Depois da Galícia, a maior audiência do Sermos é na Inglaterra, onde há uma grande comunidade galega. Mas temos leitores em toda a Europa e até no Brasil, provavelmente migrantes" (Mexuto, entrevista pessoal, junho 30, 2017).

Outra estratégia apontada por Vilameá (entrevista pessoal, julho 24, 2017) para obter assinantes e anunciantes é a busca por um jornalismo de qualidade, com diferenciais em relação aos seus concorrentes. Vilameá destaca suas ações específicas para melhorar a qualidade do produto: um novo projeto gráfico e a divisão entre as versões impressa e digital.

A equipe de redação do jornal continua a escrever para as duas versões, porém, desde 2015, cada formato possui um editor responsável: Xosé Mexuto no digital e Maria Obelleiro na edição impressa. Mexuto (entrevista pessoal, julho 24, 2017) afirma que a mudança resultou em uma maior produtividade na redação, que passou a produzir as duas versões com conteúdos bem diferentes.

"São públicos diferentes, um formato diferente, era preciso que tivesse um editor diferente. Eu entro na redação todos os dias pensando na capa do site, das notícias factuais. A Maria trabalha a planear a próxima edição impressa. Todos escrevem para os dois, mas a edição fica separada, mais organizada. Conseguimos ter dois produtos 
distintos, o hard-news em tempo real e outro com artigos mais trabalhados" (Mexuto, entrevista pessoal, julho 14 de 2017).

Nos dias da observação participante, Maria Obelleiro esteve presente na redação apenas no dia 3 de julho, para orientar uma nova estagiária, que teria mais responsabilidades com o impresso. Não há reuniões de pauta semanais para a edição impressa. Obelleiro conversa com os demais jornalistas por e-mail e telefone, e repassa as pautas a serem realizadas. Os demais integrantes da redação trabalham na sede em Santiago de Compostela e não possuem contato direto com a produção da edição em papel.

Se Xosé Mexuto, editor da edição edital, não interfere no processo de edição do semanário, o inverso também ocorre. Enquanto as edições impressas são voltadas para grandes reportagens, entrevistas e artigos de análise, a edição digital se ocupa com as notícias factuais, cobertura de eventos e textos opinativos. A edição impressa tem destaque no digital nas quintas-feiras, dia de circulação da versão em papel.

Os horários de trabalho dos jornalistas também são separados entre impresso e digital. Xosé Mexuto, Xesús Pinheiro e Rocío Castro, os três jornalistas que atuam em Santiago de Compostela, cumprem em média, sete horas, sendo quatro horas dentro da redação e três fora dela. Mexuto explica que normalmente, as horas fora da redação são ocupadas com entrevistas e reportagens para a edição impressa, enquanto as demais horas são destinadas a produção e publicação de notícias na internet.

Mexuto explica ainda que Obelleiro também produz notícias para a internet, sob coordenação dele, mas sem um horário definido, já que sua função principal no Sermos Galiza está com a edição impressa.

A administração do jornal afirmou em entrevista pessoal que o Sermos Galiza não separa a contabilidade das publicidades vendidas para as versões impressa e digital, porém, estima-se que dois terços têm origem no impresso.

A versão digital disponibiliza todo o conteúdo de forma gratuita e a principal fonte de renda são as assinaturas, o que evidencia a dependência do digital para o impresso em termos financeiros. Vilameá (entrevista pessoal, julho 24, 2017) entende que o digital tem sua importância na contabilidade da empresa, mas de forma indireta, atraindo novos leitores que podem se tornar assinantes no futuro. 


\subsection{Nacionalismo galego}

O nacionalismo galego é a principal estratégia para obtenção de assinantes e leitores, a principal fonte de receita do jornal. Vilameá (entrevista pessoal, julho 24, 2017) reforça que o jornal foi criado por um grupo de pessoas que entendia a necessidade de existir um jornal inteiramente no idioma galego, mas o nacionalismo vai além: a linha editorial da publicação é explicitamente nacionalista, em defesa dos valores culturais e da independência da região (Mexuto, entrevista pessoal, junho 30, 2017).

Mexuto (entrevista pessoal, julho 24, 2017) define o Sermos Galiza como um jornal nacionalista galego com ideais progressistas, como a defesa de bandeiras laborais, direitos humanos e minorias. A defesa da identidade cultural de uma nação é uma característica da imprensa segundo Bahia (2009), que atribui ao jornalismo a difusão desta identidade através do idioma e de elementos culturais.

A imprensa teve - e certamente mantém até os dias atuais - um papel de grande relevância para a construção de uma identidade nacional, uma vez que o estabelecimento de um projeto de nação moderna passa incontornavelmente pela afirmação da língua vernácula, o que se dá através da educação e da literatura ou da música, mas igualmente do jornalismo, que ainda se responsabiliza pela difusão e a legitimação de lideranças políticas e vultos históricos, intelectuais e artistas, identidades e estigmas. (Bahia, 2009, p.82)

O papel desempenhado pelo Sermos Galiza na defesa do idioma galego é característico do jornalismo, sobretudo do regional. Jasper (2016) explica que a imprensa sempre teve um papel importante na formação de identidades culturais, porém isto tornou-se mais evidente com a globalização. A defesa de um idioma local é a manutenção de uma cultura tradicional em uma sociedade cada vez mais globalizada.

\subsection{Análise}

O Sermos Galiza adota o padrão de plataforma multilateral ao disponibilizar um conteúdo gratuito e aberto na versão digital com o intuito de atrair novos assinantes, isto é, novas receitas para o jornal. O ceticismo com a cobrança pelo conteúdo digital foi abordado no item 2.1. Ferreira (2017) comparou a internet como um serviço básico, onde a população não vive sem, porém não concorda com a cobrança pelo uso.

Sobre utilizar um segmento do público para potencializar outro, Osterwalder e Pigneur (2011) afirmam: 
Uma maneira de resolver o problema é subsidiar um segmento de cliente. Embora o operadora da plataforma tenha custos para atender a todos os grupos de clientes, ele frequentemente opta por atrair um segmento para um lado da plataforma com uma proposta de valor barata ou gratuita, para então, subsequentemente, atrair usuários para os outros lados. Uma dificuldades encarada pelo operadora de plataforma multilateral é compreender qual lado subsidiar e como cobrar corretamente para atrair clientes. Osterwalder e Pigneur, 2011, p.78).

A estratégia utilizada pelo Sermos Galiza pode ser comparada ao modelo freemium, conforme item 2.1. Este modelo consiste em disponibilizar parte do conteúdo de forma gratuita e outra parte ser restrita a assinantes, técnica utilizada na tecnologia da informação na comercialização de softwares. No caso do jornal galego, o conteúdo "premium" está na versão impressa, que não é inteiramente disponibilizada na versão digital.

Esta estratégia semelhante ao modelo freemium complementa-se com a linha editorial do jornal. Por ter a defesa do nacionalismo galego em sua missão, o Sermos Galiza produz um conteúdo aberto digital para difundir este nacionalismo, enquanto a versão impressa, voltada aos assinantes, é para os já apoiadores da linha editorial.

A separação entre jornal impresso e digital é evidente também nas práticas da redação. Mendes (2012) aborda a necessidade da produção de um conteúdo específico para a versão digital, pois os leitores possuem hábitos diferentes na forma de consumir a notícia. No caso estudado verificou-se:

- Um editor para a versão impressa e outro para o digital.

- A divisão da carga horária dos jornalistas, que ficam na redação para produção do digital em horário pré-determinado e possuem horários livres para produção das notícias do impresso.

- As notícias publicadas na edição impressa não são usadas na totalidade no digital. Semanário impresso não atua com hard-news e não utiliza material do digital.

\section{CONCLUSÕES}

O Sermos Galiza possui dois produtos distintos, impresso e digital, com públicos diferentes: o primeiro de simpatizantes de seus posicionamentos editoriais e segundo mais amplo, visando toda a comunidade galega. Se a perda de leitores é um problema que o jornalismo impresso sofre desde a metade do século passado, no Sermos Galiza o impresso é um produto premium, voltado a um público mais selecionado. 
Conforme Mexuto (entrevista pessoal, julho 24, 2017), é uma decisão editorial não cobrar pelo conteúdo no website, porém, a página inicial sempre contém um anúncio da campanha de assinaturas da edição impressa. A mensagem por novos assinantes não utiliza as vantagens do impresso como argumento, mas foca na importância de um "jornalismo alternativo e galego". Isto é, por mais que não cobre pelo acesso, o website conduz o leitor para uma contribuição financeira, uma característica nos modelos de negócios no jornalismo digital.

Portanto, a estratégia do Sermos Galiza mostra-se eficiente pois as assinaturas correspondem a mais de $50 \%$ das receitas da empresa. O semanário galego aponta que deve ser considerado a proposta de receber recursos com um jornal digital de forma indireta.

Como o jornal possui 1,2 mil assinantes e segundo o administrador da empresa, Roberto Vilameá, a grande maioria dos acionistas são assinantes, conclui-se que a maior fonte de receita do jornal vem de seus proprietários, que financiam o próprio produto mensalmente. Acrescentando-se o fato que o jornal foi criado em 2012 já com 900 acionistas, é possível concluir que o número de assinantes externos não cresceu muito nos cinco primeiros anos.

Evidencia-se, então, um modelo de negócios a partir de um autofinanciamento, que completa-se com a proposta de ter duas edições distintas, uma impressa paga e outra gratuita digital. Na versão impressa, o jornal é produzido para um grupo mais restrito, onde boa parte é dono do meio, com um jornalismo feito com matérias analíticas e discursivas. Já a versão digital, focada em hard-news, é aberta, focada em um público muito maior, mas que não abre mão de seu posicionamento editorial.

Ao ofertar um conteúdo próprio e gratuito, mas sempre com a intenção de transformar esse leitor num assinante, somado ao posicionamento político da empresa, pode-se afirmar que o Sermos Galiza é um instrumento de um segmento da sociedade galega, os defensores do nacionalismo da comunidade, para ampliar e difundir suas ideias: quem adere a causa vira assinante e ajuda a trazer mais leitores para o projeto.

\section{Notas}

${ }^{1}$ https://mediamapa.gal/ 


\section{Referências}

Bahia, J. P. D. (2009). Ser baiano na medida do recôncavo: o jornalismo regional como elemento formador de identidade (tese de doutorado, Universidade Federal da Bahia). Disponível em https://repositorio.ufba.br/ri/bitstream/ri/10833/1/dissert_Jos\%c3\%a9\%20Bahia.pdf.

Bastos, H. (2006). Ciberjornalismo: dos primórdios ao impasse. Comunicação e Sociedade. 9-10, 103-112. Disponível em: http://revistacomsoc.pt/index.php/comsoc/article/view/1158/1101

Bezerra, A. K. G. (2010). A pesquisa etnográfica e as especificidades da observação participante. Vinheta, (1), 01-18. Disponível em http://www.academia.edu/24502157/A_pesquisa_etnogr\%C3\%A1fica_e_as_especificidade s_da_observa\%C3\%A7\%C3\%A3o_participante.

Borges, S. (2009). A segunda fase do Jornalismo Público. Estudos em Comunicação. (5), 95-113. Disponível em: http://www.ec.ubi.pt/ec/05/pdf/05-borges-segunda.pdf.

Borges, Z. (2016). 1.400 jornalistas demitidos em 2015. Acesso em 8 março, 2018 em http://observatoriodaimprensa.com.br/imprensa-em-questao/1-400-jornalistas-demitidosem-2015.

Braga, C. F., Tuzzo, S. A. (2016). O processo de triangulação da pesquisa qualitativa: o metafenômeno como gênese. Revista Pesquisa Qualitativa. 4(5), 140-158. Disponível em http://rpq.revista.sepq.org.br/index.php/rpq/article/view/38.

Camponez, C. (2002). Jornalismo de proximidade : rituais de comunicação na imprensa regional. Coimbra: Minerva.

Canavilhas, J. M. (2007). Webnoticia: propuesta de modelo periodístico para la WWW. Covilhã, Livros LabCom.

Correia, J. C. (1998). Jornalismo regional e cidadania. Disponível em: http://www.bocc.ubi.pt/pag/correia-joao-jornalismo-regional.pdf.

Costa, C. T. (2014). Um modelo de negócio para o jornalismo digital. Revista de Jornalismo ESPM. (9), 51-115.

Couto, P. F. (2010). Ciberjornalismo regional: aproveitamento das potencialidades da Web dos nove jornais regionais com maior audiência do Distrito do Porto (dissertação de mestrado, Universidade do Porto). Disponível em: https://repositorio-aberto.up.pt/handle/10216/55917.

Durães, P. (2017). APCT: diários generalistas venderam menos 17.538 exemplares/dia nos primeiros quatro meses do ano. Acesso em 29 setembro, $2017 \mathrm{em}$ http://www.meiosepublicidade.pt/2017/06/apct-diarios-generalistas-venderam-menos-17538-exemplaresdia-nos-primeiros-quatro-meses-do-ano. 
Ferreira, R. S. (2017). Twitter pondera começar a cobrar (mas há quem pague?). Acesso em 7 agosto, 2017 em https://www.dn.pt/opiniao/opiniao-dn/ricardo-simoes-ferreira/interior/twitterpondera-comecar-a-cobrar-mas-ha-quem-pague-5749951.html.

Fino, C. N. (2008). A etnografia enquanto método: um modo de entender as culturas (escolares) locais. In Christine Escallier e Nelson Veríssimo (Org.) Educação e cultura (pp. 43-53). Disponível em https://digituma.uma.pt/handle/10400.13/809.

Franklin, B., Murphy, D. (1991). Whats News? The Market, Politics and the Local Press. Londres: Routledge.

García, X. L. (2008). Doce años de experimentación ciberperiodística desde Galicia: luces y sombras. Textual \& Visual Media: revista de la Sociedad Española de Periodística, 1, 205-212. Disponível em http://textualvisualmedia.com/images/revistas/01/10_lopez.pdf.

García, X. L., Negreira-Rey, M. C. (2016). La dimensión informativa del ciberperiodismo hiperlocal en Galicia. II Simposio de la Red Internacional de Investigación de Gestión de la Comunicación. 271-283. Disponível em https://xescom2016. files.wordpress.com/2017/01/documento-xescom.pdf.

Gascón, J. F. F. (2010). Impacto visual da imprensa digital - uma pesquisa espanhola empírica. Brazilian Journalism Research. 6(2), 120-137. Disponível em https://bjr.sbpjor.org.br/bjr/article/download/28/29.

Godoy, A. S. (1995). Pesquisa qualitativa - tipos fundamentais. Revista de Administração de Empresas. 35(3), 20-29. Disponível em http://bibliotecadigital.fgv.br/ojs/index.php/rae/article/view/38200.

Hindman, M. (2015). Stickier News, What Newspapers Don't Know about Web Traffic Has Hurt Them Badly - But There is a Better Way. Disponível em: https://shorensteincenter.org/stickiernews-matthew-hindman.

Jasper, A. (2016). Marcas de um jornalismo regional: identidade cultural gaúcha nos diários paranaenses (dissertação de mestrado, Universidade Estadual de Ponta Grossa). Disponível em http://tede2.uepg.br/jspui/handle/prefix/56.

Jerónimo, P. (2015). Ciberjornalismo de Proximidade. Covilhã: Livros LabCom. Disponível em http://www.labcom-ifp.ubi.pt/book/203.

Junior, W. T. L. (2007). Precursores do jornalismo On-line. V Congresso Nacional de História da Mídia. Disponível em http://www.intercom.org.br/papers/outros/hmidia2007/resumos/R00491.pdf. 
Mendes, A. C. (2012). Novos modelos de negócio para a imprensa online: o modelo fremium no publico.pt, no elpais.com e no nytimes.com (dissertação de mestrado, Instituto Politécnico de Portalegre). Disponível em https://pt.scribd.com/document/114889927/Novos-Modelosde-Negocio-Para-a-Imprensa-Online-o-Modelo-Freemium-No-Publico-pt-No-Elpais-com-eNo-Nytimes-com-Angela-Mendes.

Nunes, D. F. (2017). New York Times volta aos lucros graças às assinaturas digitais. Acesso em 03 de fevereiro de $2018 \mathrm{em}$ : https://www.dinheirovivo.pt/empresas/new-york-times-volta-aoslucros-gracas-as-assinaturas-digitais.

Orofino, M. A. R. (2011). Técnicas de criação do conhecimento no desenvolvimento de modelos de negócio (dissertação de mestrado, Universidade Federal de Santa Catarina). Disponível em https://repositorio.ufsc.br/handle/123456789/95255.

Pacete, L. G. (2015). Brasil perdeu oito jornais em 6 anos. Acesso em 25 maio, 2017 em http://www.meioemensagem.com.br/home/midia/2015/07/15/brasil-perdeu-oito-jornais-em6-anos.html.

Pereira, L. F. D. R. (2002). O Adiantado do Minuto: A internet e os novos rumos do jornalismo. Disponível em http://bocc.ubi.pt/pag/pereira-luis-novos-rumos-do-jornalismo.html.

Pereira, J. P. (2014). Assinaturas digitais dos jornais diários mais do que duplicam. Acesso em 26 de junho de 2017 em https://www.publico.pt/2014/08/29/portugal/noticia/assinaturas-digitaisdos-diarios-mais-do-que-duplicam-1668081.

Pinheiro, G. (2009). De quando é o primeiro jornal online? Que tal 1981?. Acesso em 15 de julho de 2017 em https://brasil.estadao.com.br/blogs/macaco-eletrico/de-quando-e-o-primeiro-jornalonline-que-tal-1981.

Robertson, R. (1995). Glocalization: Time-Space and Homogeneity. In Featherstone, M., Lash, S., Robertson, R. (Eds.), Global Modernities (pp. 25-44). Londres: SAGE Publications.

Salaverría, R. (2016). España. In Salaverría, R. (Ed.), Ciberperiodismo en Iberoamérica (pp. 169210). Madrí: Fundación Telefónica.

Silva, L. L. D. (2015). Inovação disruptiva no modelo de negócio da imprensa generalista portuguesa (dissertação de Mestrado, Instituto Superior de Economia e Gestão) Disponível em https://www.iseg.ulisboa.pt/aquila/getFile.do?fileld=679910\&method=getFile.

Stake, R. E. (2016). A Arte da Investigação com Estudos de Caso. Lisboa: Fundação Calouste Gulbenkian.

Stephens, M. (2014). Beyond News - The Future of Journalism. Nova lorque: Columbia University Press. 
Temer, A. C. R. P., Tuzzo, S. A. (2017). A entrevista como método de pesquisa qualitativa: uma Leitura Crítica das memórias dos jornalistas. Atas - Investigação Qualitativas em Ciências Sociais. 3 4 459-468. Disponível em http://proceedings.ciaiq.org/index.php/ciaiq2017/article/view/1419. 